\title{
Water balance study on green roof in Brazil
}

\begin{abstract}
The present study aims to investigate the water balance in conventional and green roofs and also to monitor the development of peanut grass (Arachis repens Handro), relating the type of vegetation cover or not with its water retention capacity and, consequently, to obtain the coefficient of runoff for each scenario tested. The scenarios tested were: (1) conventional collection surface with fiber cement tile, (2) green roof structure with substrate and no plant, and (3) planted green roof. The rains incident on the roof were obtained for the city of Itajubá, in Minas Gerais, by the curve of i-d-f with 5min of duration and 5years of return period according to the recommendation of NBR 10844 (ABNT,1989). The volumes of storm water runoff and drained from the bottom of the roofs studied were collected in calibrated graduated containers. It was concluded that: the peanut grass showed satisfactory development and high recovery capacity; the peanut grass took only $1 \frac{1 / 2}{2}$ month to cover the entire roof; the coefficient of runoff of the green roof for intense rainy season was on average 0.569 and in the dry season it was 0.003 . While the conventional roof presented average surface runoff coefficient of 0.995 for the rainy season and 0.901 for the dry season; the component of the green roof that contributed most to the rainwater retention was the substrate. Therefore, attention should be paid to the choice of substrate so that it can adequately grow the plant, retain rainwater and not contaminate the bottom drainage water of the roof that can be used for less noble uses.
\end{abstract}

Keywords: green infrastructure, runoff coefficient, rainwater retention
Volume 4 Issue 4 - 2020

\author{
Calheiros Herlane Costa, Silva Fernanda \\ Gomes Gonçalves, Costa Luisa Silva, Silva \\ Matheus Lins Macedo \\ Federal University of Itajubá, Brazil
}

Correspondence: Calheiros Herlane Costa, UNIFEl: Federal University of Itajubá, IRN - Av. BPS, Pinheirinho, 37500-903, Itajubá - MG, Brazil, Email h2hc@unifei.edu.br

Received: July 08, 2020 | Published: July 2I, 2020

\section{Introduction}

According to Zhang and Chui, ${ }^{1}$ green infrastructure mitigates the negative effects of urbanization and provides hydrological and bioecological benefits. However, these benefits are highly dependent on scale. They conclude that smaller scale benefits establish the basis for larger scale benefits and identify that there is a research gap in studies related to rain water harvesting, recommending further studies on this scale. Like wise, Akther et al. ${ }^{2}$ highlight the need for specific studies of the region or location to implement green roofs with confidence.

Gong et $\mathrm{al}^{3}{ }^{3}$ studied the flow retention effectiveness of green roof modules and concluded that heavy rains $(>25 \mathrm{~mm})$ significantly affect there tention performance of extensive greenroofs in then extrainyevent.

Whereas, a conventional roof, according to Gribbin, ${ }^{4}$ has a design run off coefficient in the range of 0.75 to 0.95 (onaverage 0.85 ; thatis, $15 \%$ retention). According to Liptan and Strecker, ${ }^{5}$ when using the greenroof, there tention of the volume of precipitation can varyfrom $10 \%$ to $35 \%$ during the rainy season and from $65 \%$ to $100 \%$ during the dry season and there duction of drainage rates can reach $45 \%$, which canmean a significant decrease in the contribution of floods in urban centers.

The study by Palla et al. ${ }^{6}$ demonstrated that the implementation of greenroofs can reduce the peak of runoff and the delay time between 7 and 15minutes of the runoff volume (detentioneffect); while, after the introduction of a drought-related process related to evapotranspiration, it ispossibleto observe a reduction in the volume ofrunoff (retentioneffect).

Plants are a critical component of greenroofs and, according to Zhang et al. ${ }^{7}$ it is believed that plants with high water use after rain, but which are also drought to lerant, can improve rain retention on greenroofs. The authors found that some monoculture shad greater rain water retention and that some plants created preferential flow path ways, resulting in lower water content in thes ubstrate, which reduced rain retention. Therefore, they suggested that the characteristics of the root and its interaction with thes ubstrates should be considered together with water use strategies for rain retention on greenroofs.

The present study seeks to investigate the water balance in conventional and greenroofs and also to monitor the development of peanutgrass (Arachisrepens Handro), relating the type of vegetation cover or not with its water retention capacity and, consequently, obtain the runoff coefficient for each scenario tested.

\section{Methodology}

This experimental research was carried out in Itajubá in the south of the state of Minas Gerais, which has a characteristic climate of mountain regions. The experimental installation consists of four planted modules and one non-planted module, as well as a fiber cement roof with a $25 \%$ slope. The growth of the Arachisrepens Handro (peanutgrass) plants was monitored and the meteorological variables obtained from the Weather Forecast and Climate Studies Center of Brazil - CPTEC/INPE were recorded. After the closure of the vegetation cover, the water balance was performed in each of the three types of cover.

The monitoring of plant growth was carried out using the quadrants method. ${ }^{8}$ In addition to plant growth, the average length of the main vegetation branch, then umber of branches and then umber of leaves were monitored, using a numerical counter and caliper.

A rain simulator was developed to carry out the tests in order to keep the volume of the simulated rain constant. The simulated rain intensity is the maximum intensity lasting 5minutes and a return 
period of 5years, obtained from the intensity-duration-frequency curve of Itajubá - MG, as recommended by the Brazilian standard for the design of storm water building installations, NBR $10844 .{ }^{9}$

The water balance wasper formed and the runoff coefficient was obtained by the ratio between the runoff flow and the precipitation on the roof. ${ }^{10}$ The surface runoff coefficient of conventional fiber cement roof recommended by Pacey and Cullis ${ }^{11}$ for design is 0.8 . The volumes of rain water incident on the roofs, drained superficially and drained from the bottom of the studied roofs were collected in calibrated graduated containers. All results were analyzed statistically. For the comparison of means, analysis of variance (ANOVA) was used to compare the modules with each other and Tukey's test to compare the monitored parameters.

\section{Results}

\section{Plantgrowth}

On September 12, 2018, four seedlings of peanut grass were planted in each roof module arranged in anuneven and non-aligned way to facilitate the closing of the vegetation. On that day, the average values recorded for the control parameters were: $8.62 \pm 0.76 \mathrm{~cm}$ in length of the mainstem, $5.4 \pm 1.0$ shoots per seedling and $4.4 \pm 1.0$ branches with 4 leaves per bud (96.5 \pm 34 .4leaves per seedling). Figures $1 \& 2$ illustrate the development of vegetation growth in the four modules of the greenroof, photographs taken on October 5 and 26,2018 respectively.
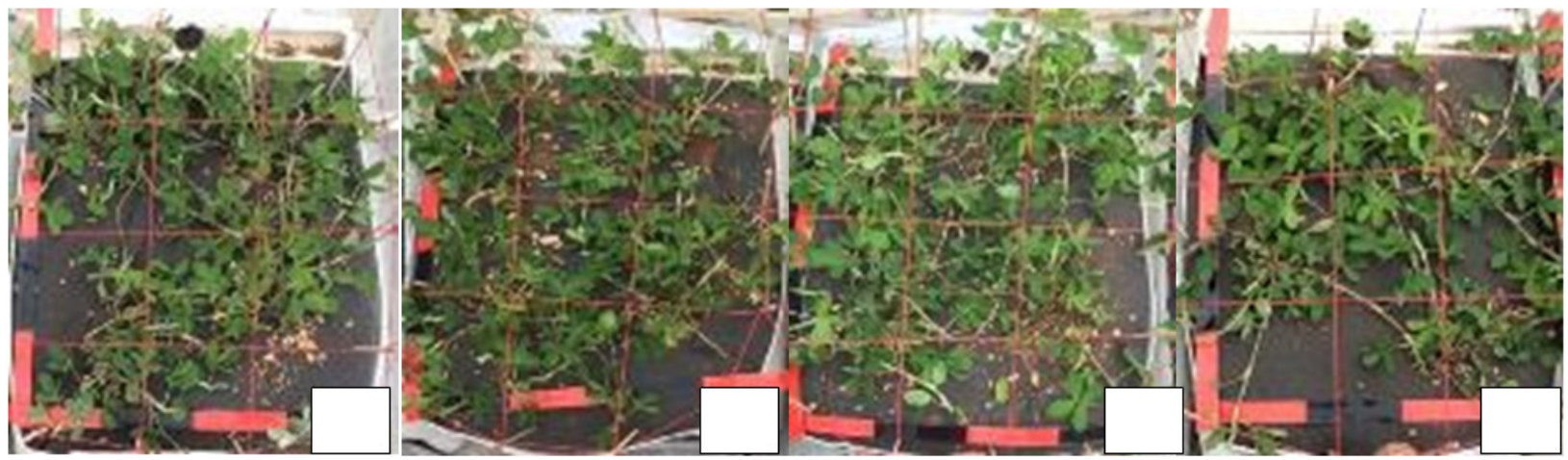

Figure I Measurement of plant growth on October 5, 2018 in modules I to 4 using the quadrants method. Fonte:Author himself.
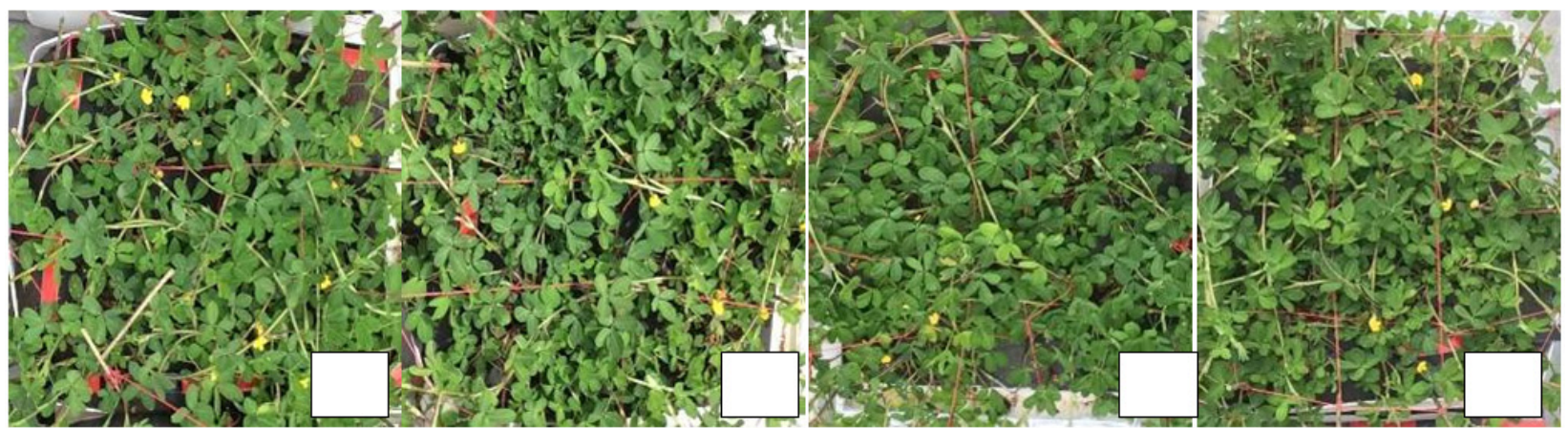

Figure 2 Measurement of plant growth on October 26, 2018 in modules I to 4 using the quadrants method.

Fonte:Author himself.

Figure 3 shows the evolution of the plant's growth over time, where it can be seen that, in just 33 days, there was an increase in the coverage rate by an average of $77 \%$, that is, more than $2 / 3$ of the module was covered. The complete coverage of all modules occurred after one and a half months of planting these edlings.

The results observe dafter 23 days of planting, on average, were: $12.40 \pm 0.87 \mathrm{~cm}$ in length of the mainstem, $6.0 \pm 1.0$ buds per seedling and 6 branches with 4 leaves per bud $(239.8 \pm 83.9$ leaves per seedling). The average length of the mainstem, considering all planted modules, after 33 days of planting was $17.87 \pm 3.52 \mathrm{~cm}$ and after a monthand a half it was $22.40 \pm 3.44 \mathrm{~cm}$. Accordingto Rodrigues et al. ${ }^{12}$ reaches a heightof $20-40 \mathrm{~cm}$. All monitored parameters were analyzed statistically by ANOVA and it was found that there was no significant difference between the results of each module $(\mathrm{F}<$ critical $\mathrm{F}$ and $\mathrm{p}$-value $>0.05$ ), indicating that the growth occurred in a similar way in all four green roof modules. The Tukey test indicated that there is no statistically significant difference between the length of the stem, the number of shoots and the number of branches to monitor the growth of the grass. However, the vegetation cover rate and the number of leaves differ significantly from the other parameters.

According to data from CPTEC/INPE, in Itajubá - MG - Brazil, in September 2018 there was a total rainfall in the range of 50-100 $\mathrm{mm}$, while in October it was $100-150 \mathrm{~mm}$. Thatis, even in conditionsof intense rain in the region during the adaptation period, since this species develops better in conditions of full sun, the vegetation showed satisfactory development, with no degeneration of any seedling of the four modules planted, ie $100 \%$ of survival.

During the period of monitoring plant growth, events occurred (drought, lack of irrigation and attack by leaf-cutting ants) that affected their leaf cover. However, the problem was soon remedied and the vegetation recovered by covering the roof again in just a single week. 

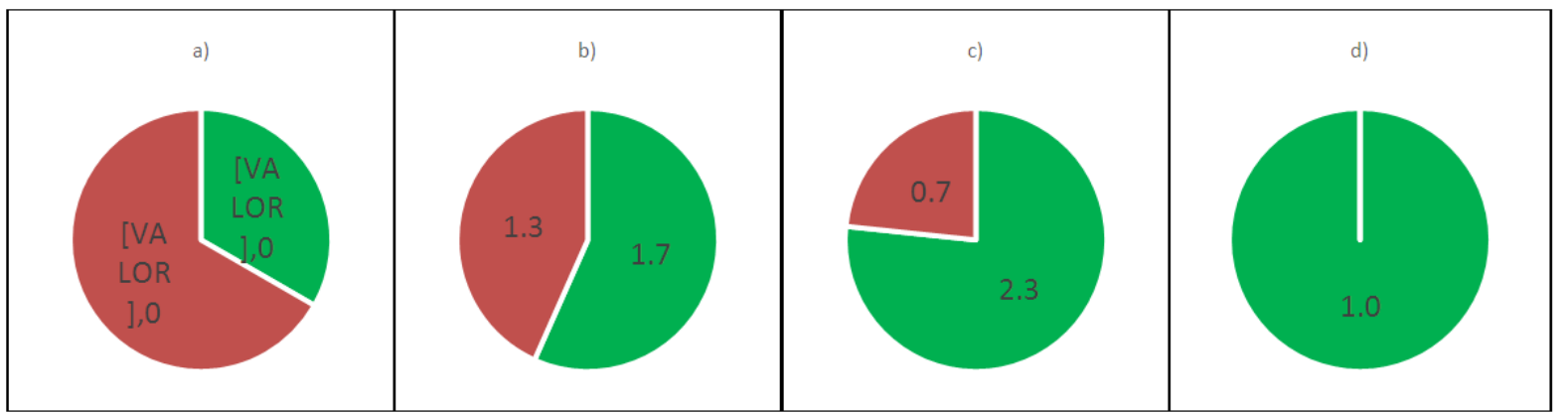

Figura 3 Coverage of modules by vegetation over the monitoring time: a) 09/12/2018; b) 10/05/2018; c) 10/15/2018; d) $10 / 26 / 2018$ (o- with vegetation, owithout vegetation).

Fonte:Author himself.

\section{Runoff coefficient}

The runoff coefficient was determined during the rainy season (Nov-Dec / 2018) and in the dry season (May-Jun / 2019), performing the water balance for three scenarios: conventional roof, green roof and, also, roof with substrate and without plant.

In the rainy season, there sults were as follows: the value of the runoff coefficient of the modules with vegetation was onaverage $0.569 \pm 0.068$, the module without vegetation and the conventional tile were $0.654 \pm 0.000$ and $0.995 \pm 0.000$, respectively. Note that the greatest retention of runoff occurs in the vegetated modules, followed by the module without a plant and with substrate, and then by the tile without a plant and without substrate. Indicating the importance of the type and thickness of the peanut grass substrate, which contributed to there tention of $43.1 \%$ (with $34.6 \%$ being retained in thes ubstrate) of precipitated rain water on the green cover.

In the dry season, the value of the runoff coefficient of the modules with vegetation was on average $0.003 \pm 0.008$, for the module without vegetation and the fiber cement tile were $0.552 \pm 0.087$ and $0.901 \pm 0.000$, respectively. The results reveal that in the dry season practically all rain water is retained in the green roof, the substrate is responsible for the retention of $44.8 \%$ of this value and the plant $54.9 \%$. Meanwhile, the conventional fiber cement roof allows the flowof $90.1 \%$ of the raincaptured on its surface.

These results are in line with other studies, such as those by Liptan and Strecker, ${ }^{5}$ Palla et al. ${ }^{6}$ Zhang et al. ${ }^{7}$ In addition to verifying that the increase in the intensity of rain, the differences between the values of the runoff coefficients of the different coverings are smaller, as observed by Cavalcanti. ${ }^{13}$

\section{Conclusion}

With this work it can be concluded that:

i. The choice of peanut grass for the green roof was appropriate for the region of Itajubá - MG, and presented satisfactory development and high recovery capacity, even in conditions of intense rain or drought.

ii. The vegetation in about a month and a half cover edall the modules that make up the green roof and reached $22.4 \pm 3.4 \mathrm{~cm}$ in length of the mainstem, presenting leaves and flowers.

iii. The results revealed that the average green roof precipitation volume retention was $43.1 \%$ during the rainy season and $99.7 \%$ during thedry season, confirming previous research. iv. The conventional fiber cement roof had runoff coefficients of 0.995 and 0.901 respectively during the period of intense rain and in the dry season. Values above those normally used in rain water orurband rainage projects. Probably dueto the high slope of the roof.

v. The green roof component that contributed mostto rainwater retention was the substrate. Therefore, all attention should be given to choosing the substrates ot hat it can allow the plant to grow properly, retain rainwater and not contaminate the bottom drainage water of the roof that canbe used for lessnoble uses.

\section{Acknowledgments}

To CNPq and FAPEMIG, for the support received.

\section{Conflicts of interest}

Authors declare ha here is no conflict of interest.

\section{Funding}

None.

\section{References}

1. Zhang Kun, Chui, Ting Fong May. Linking hydrological and bioecological benefits of green infrastructures across spatial scales - A literature review. Science of the Total Environment. 2019;646:1219-1231.

2. AKTHER M, HE J, CHU A, et al. A Review of Green Roof Applications for Managing Urban Stormwater in Different Climatic Zones. Sustainability. 2018;10(8):2864-2892.

3. Gong, Yongwei Yin, Dingkun Fang, et al. Factors Affecting Runoff Retention Performance of Extensive Green Roofs. Water. 2018;10(9):1217-1232.

4. GRIBBIN, John E. Introduction to hydraulics, hydrology and stormwater management. North American $3^{\text {rd }}$ edition translation. Editora Cengage Learning. 2009;494.

5. Liptan T, Strecker E. Ecoroofs (Greenroofs) - A More Sustainable Infrastructure. Proceedings National Conference on Urban Storm Water: Enhancing Programs at the Local Level, Chicago, IL, U.S. Environmental Protection Agency. 2003:198-214.

6. Palla A, Berretta C, Lanza LG, et al. Modeling storm water control operated by green roofs at the urban catchment scale. Proceedings $11^{\text {th }}$ Int. Conf. on Urban Drainage, Edinburgh, Scotland, UK. 2008:1-10.

7. Zhang Zheng, Szota Christopher, Fletcher Tim D, et al. Influence of plant composition and water use strategies on green roof stormwater retention. The Science of the total environment. 2018;625:775-781. 
8. Oliveira Flavia, Rakocevic Miroslava. Adaptation of a method to measure the leaf area index (iaf) and its application to brachiaria (brachiariabrizanthahochstex a. Rich) in a silvopastoral system in northwest Paraná. II Evento de iniciação cientifica da Embrapa florestas. 2003.

9. ABNT - Associação Brasileira De Normas Técnicas. NBR10844: Building installations for rainwater - procedure. Rio de Janeiro; 1989.

10. Gould J, Nissen-petersen E. Rainwater Catchment Systems for Domestic Supply. International Technology Publications, London, United Kingdom; 1999.
11. Pacey Arnold, Cullis Adrian. Rainwater Harvesting: The Collection of Rainfall and Runoff in Rural Area. International Technology Publications, London, United Kingdom; 1989.

12. Rodrigues Antonia Alice C, Silva Gilson S, Moraes Flávio HR, et al. Arachisrepens: new host of Pucciniaarachidis. Fitopatologia brasileira (notas fitopatológicas). 2006;31(4):401-411.

13. Cavalcanti, Nilton de Brito. Effect of rainwater runoff on different roofs. Environmental Engineering Magazine - Espírito Santo do Pinhal. 2010;7(4):201-210. Cavalcanti, Nilton de Brito. Effect of rainwater runoff on different roofs. Environmental Engineering Magazine - Espírito Santo do Pinhal. 2010;7(4):201-210. 